\title{
Disproportionate mitral regurgitation: another myth? A critical appraisal of echocardiographic assessment of functional mitral regurgitation
}

\author{
Andreas Hagendorff',11 (D) $\cdot$ Fabian Knebel ${ }^{2,3} \cdot$ Andreas Helfen $^{4,5} \cdot$ Stephan Stöbe $^{1} \cdot$ Torsten Doenst $^{6}$. \\ Volkmar Falk 7,8,9,10
}

Received: 1 June 2020 / Accepted: 17 August 2020 / Published online: 26 August 2020

(c) The Author(s) 2020

\begin{abstract}
The contradictory findings of recent prospective randomized controlled trials assessing the impact of percutaneous edgeto-edge repair in patients with functional or secondary mitral regurgitation have triggered a lively discussion about an "integrated" echocardiographic approach for grading severity of mitral regurgitation. In the MITRA-FR trial, the COAPT trial and the REDUCE-FMR trial echocardiographic assessment of the severity of mitral regurgitation was consistent with principles set forth by the current echocardiographic guidelines and analysed in its best settings by expert international leaders in the field of echocardiography. However, serious inconsistencies appeared in the presented echocardiographic assessments regarding cardiac output and regurgitant fraction. A new term "disproportionate functional mitral regurgitation" was introduced describing a situation where the increase of effective regurgitant orifice area exceeds the enlargement of the left ventricular end-diastolic volumes. Further discussion resulted in the idea of a "new conceptional framework" for distinguishing "proportionate" and "disproportionate" functional mitral regurgitation. The aim of this viewpoint is to dispute conclusions based on the term "disproportionate" mitral regurgitation. A "disproportionate" FMR is highly questionable because disproportionateness of flow in communication vessels cannot exist. In addition, a proposal of echocardiographic assessment based on a conventional comprehensive transthoracic echocardiography is given to avoid obvious hemodynamic contradictions.
\end{abstract}

Keywords Functional mitral regurgitation · Disproportionate mitral regurgitation $\cdot$ Hemodynamics $\cdot$ Regurgitant fraction $\cdot$ Echocardiography

Hagendorff Disproportionate FMR—Another Myth?

Andreas Hagendorff

Andreas.Hagendorff@medizin.uni-leipzig.de

1 Department of Cardiology, University of Leipzig, Leipzig, Germany

2 Department of Cardiology, University of Berlin, Charité-Universitätsmedizin Berlin, Berlin, Germany

3 Speaker of the Working Group „Cardiovascular Ultrasound“ of the German Society of Cardiology, Düsseldorf, Germany

4 Department of Cardiology, St. Marien Hospital Lünen, Lünen, Germany

5 Co-Speaker of the Working Group „Cardiovascular Ultrasound" of the German Society of Cardiology, Düsseldorf, Germany

6 Department of Cardiothoracic Surgery, Jena University Hospital, Friedrich Schiller University of Jena, Jena, Germany
7 Department of Cardiothoracic and Vascular Surgery, University of Berlin, Charité-Universitätsmedizin Berlin, Berlin, Germany

8 Department of Cardiothoracic and Vascular Surgery, German Heart Center Berlin, Berlin, Germany

9 Department of Health Science and Technology, Swiss Federal Institute of Technology, Zurich, Switzerland

10 German Center of Cardiovascular Research, Partner Site Berlin, Berlin, Germany

11 Department of Cardiology, University Hospital Leipzig, Liebigstrasse 20, 04103 Leipzig, Germany 


\section{Background}

Inconsistencies between the left ventricular (LV) total stroke volume $\left(\mathrm{LVSV}_{\text {tot }}\right)$ obtained with two-dimensional (2D) planimetry by transthoracic echocardiography (TTE), the Doppler-derived effective LV forward SV $\left(\mathrm{LVSV}_{\text {eff }}\right)$ and the mitral regurgitant volume $\left(\mathrm{Reg} \mathrm{Vol}_{\mathrm{MV}}\right)$ obtained with the 2D proximal isovelocity surface area (2D-PISA)method can be observed in all recent transcatheter mitral valve repair (TMVR) trials [1-3]. Taken together, the mean values of the echocardiographic parameters presented in these trials characterize a hemodynamic state resembling conditions below cardiogenic shock index or inconsistent with severe functional mitral regurgitation, FMR [4-7]. The so-called "integrated approach" of grading FMR severity can be scrutinised because the characterization of the hemodynamics by echocardiography in patients with FMR obviously had failed [8,9]. Thus, a proposal like ,a specific integrative multiparametric MR grading algorithm that could identify a homogeneous population that would benefit from TMVR" [10] is in doubt. This viewpoint might contribute to the scientific debate for the need of more conclusive echocardiographic FMR assessment as applied in the recent TMVR trials. In light of the fact, that the echocardiography performed in the TMVR trials is presumably divisions above whatever is done in routine practice, and data analysis was performed by international expert leaders, the attempts to explain the differences of inconsistent echocardiographic data [1-7, 10-23] have to be critically discussed. If we still want to use echocardiography to assess FMR, because it is the most common tool, which can be used, we need substantial methodological improvements.

The first objective of this viewpoint is to discuss whether a "disproportionate" FMR can be possible anyway with the conclusion that disproportionateness of flow in communication vessels cannot exist. The second objective is to propose an extended transparent echocardiographic protocol focusing on hemodynamic plausibility to improve the grading FMR severity.

\section{General rheological considerations in valvular heart diseases}

The calculation of the effective orifice area by the continuity equation is an accepted method for echocardiographic grading of aortic valve (AV) severity based on the physical laws of conservation of mass and energy. These principles cannot be neglected meaning that blood flow velocities at defined orifices are proportional in a system of communicating tubes. If we assume "pure" aortic valve stenosis (AS), and if cross sectional areas are known at the level of the left ventricular outflow tract (LVOT) as well as at the level of the stenotic orifice area, LVSV $_{\text {tot }}$ can be measured at the level of the LVOT as well as at the level of the stenotic orifice area by Doppler echocardiography, because volume flow has to be the same at both levels $[24,25]$. In "pure" mitral regurgitation the same principle can be applied at the regurgitant orifice area; $\mathrm{RegVol}_{\mathrm{MV}}$ is the calculated difference $L_{V S V}$ tot $-\mathrm{LVSV}_{\text {eff }}$. Thus, if forward stroke volume $\mathrm{LVSV}_{\text {eff }}$ is known, the interrelationship between effective regurgitant orifice area (EROA) and regurgitant flow can be calculated due to physical laws of rheology (Fig. 1).

To introduce into the hemodynamic discussion in FMR the parameters cardiac output (CO) and the cardiac index (CI) determined by the $\mathrm{LVSV}_{\text {eff }}$, heart rate (HR) and body surface area (BSA) should be the basis of the physiological thinking in echocardiography. Further important cardiac parameters are the LV end-diastolic volume (LVEDV) and the LV ejection fraction (LVEF) to interpret the cardiovascular physiology. Normal $\mathrm{CO}$ is defined within ranges of 4.0 to $4.5 \mathrm{l} / \mathrm{min}$ or a CI of about $2.5 \mathrm{l} / \mathrm{min} / \mathrm{m}^{2}$. A CI $<2.21 / \mathrm{min} / \mathrm{m}^{2}$ is a criterium for cardiogenic shock $(\mathrm{CO}<$ about $4 \mathrm{l} / \mathrm{min})$. A normal heart rate at rest-and the target heart rate for cardiovascular patients with optimal medical treatment (OMT) - is within the ranges of 50 to $70 / \mathrm{min}$. With respect to these values of a normal cardiovascular physiology a borderline region to differentiate between normal conditions and cardiac decompensation can be marked in a $\mathrm{LVSV}_{\text {eff }}-\mathrm{LVEDV}$ diagram with respect to different LVEF (Fig. 2). To ensure sufficient cardiac output it is obvious that no mitral as well as aortic regurgitation is present, because $\mathrm{LVSV}_{\text {tot }}$ must be equal to $\operatorname{LVSV}_{\text {eff }}$ (Fig. 2).

If the mean values of LVSV TMVR trials [1-3] are put into the diagram of Fig. 2, the colored dots represent the respective relationships (Fig. 3). Table 1 illustrates the hemodynamic parameters of the recent TMVR trials reported in the literature as well as the assumptions resulting from logical calculations of the presented data [1-3]. To explain the differences in the COAPT trial version 1 is corresponding to the presented data of the original paper [2], version 2 is corresponding to the authors reply to the letter to the editor [4]. In this reply the authors issued the statement "The actual mean forward stroke volume in the COAPT trial as measured with Doppler was $51 \mathrm{ml}$, and the regurgitant volume as measured with the use of the PISA method was $59 \mathrm{ml}$, values that are consistent with severe mitral regurgitation" $[4,17,18]$. However, if the forward stroke volume is subtracted from the $\mathrm{LVSV}_{\text {tot }}$, the RegVol $\mathrm{MV}_{\mathrm{MV}}$ is only $8 \mathrm{ml}$, revealing a difference of $51 \mathrm{ml} \mathrm{RegVol}{ }_{\mathrm{MV}}$ $\left(\mathrm{RegVol}_{\mathrm{MV}}=\mathrm{LVSV}_{\mathrm{tot}}-\mathrm{LVSV}_{\mathrm{eff}}\right)$ or a difference of $51 \mathrm{ml}$ 


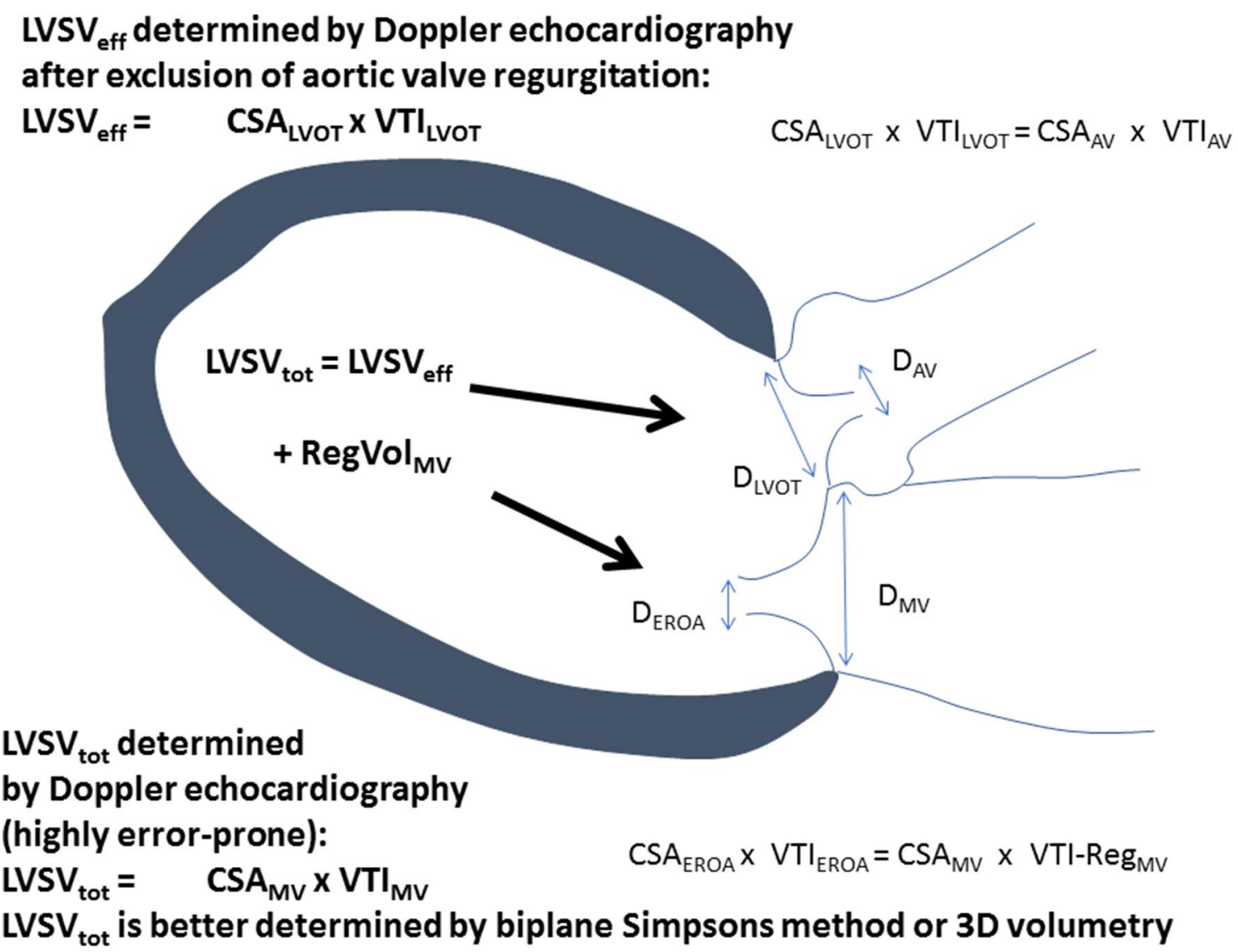

Fig. 1 Illustration of the proportionality between cross sectional areas and forward and backward systolic blood flow in the left ventricle as a system of communicating tubes. Transmitral regurgitant blood flow volume is proportional to the regurgitant orifice area, if a single timepoint measurement is performed by echocardiography. $C S A_{A V}$ cross section area of the aortic valve orifice, $C S A_{E R O A}$ cross section area of the mitral valve regurgitant orifice, $C S A_{L V O T}$ cross section area of the left ventricular outflow tract, $C S A_{M V}$ cross section area at the level of the mitral valve annulus, $D_{A V}$ diameter of the aortic valve orifice, $D_{E R O A}$ diameter of the mitral valve regurgitant orifice, $D_{L V O T}$ diameter of the left ventricular outflow tract, $D_{M V}$ diameter at the level of

$\mathrm{LVSV}_{\text {tot }}\left(\mathrm{LVSV}_{\text {tot }}=\mathrm{LVSV}_{\text {eff }}+\operatorname{RegVol}_{\mathrm{MV}}\right)$ in the device group, which is not explained by the COAPT authors (Table 1).

As mentioned above, $\mathrm{CO}$ and $\mathrm{CI}$ are represented by the multiplication of $\mathrm{LVSV}_{\text {eff }} \times \mathrm{HR}$ and not by the multiplication of $\mathrm{LVSV}_{\text {tot }} \times$ HR. Describing the conditions of a LVEDV of $200 \mathrm{ml}$ and a LVEF of $30 \%$ at a normal HR of $65 / \mathrm{min}$, the periphery needs the complete $60 \mathrm{ml}$ of the $\mathrm{LVSV}_{\text {tot }}$ as $\mathrm{LVSV}_{\text {eff }}$ to ensure sufficient normal CO or CI as illustrated by the red dot (Fig. 3). If moderate FMR with a regurgitant fraction $(\mathrm{RF})$ of $33 \%$ is assumed, this left ventricle is characterized by a LVEDV of $300 \mathrm{ml}$ at a LVEF of $30 \%$ or by a LVEDV of $200 \mathrm{ml}$ at a LVEF of $45 \%$ (brightened red dot in Fig. 3). If severe FMR with a RF of $50 \%$ is assumed, this left ventricle is characterized by a LVEDV of $400 \mathrm{ml}$ at a the mitral valve annulus, $L V S V_{\text {eff }}$ left ventricular effective stroke volume, $L V S V_{\text {tot }}$ left ventricular total stroke volume, $\operatorname{RegVol}_{M V}$ transmitral regurgitant volume, $V T I_{A V}$ velocity time integral of the systolic forward blood flow through the aortic valve orifice, $V T I_{E R O A}$ velocity time integral of the diastolic backward blood flow through the mitral valve regurgitant orifice, $V T I_{L V O T}$ velocity time integral of the systolic forward blood flow through the left ventricular outflow tract, $V T I_{M V}$ velocity time integral of the diastolic forward mitral flow at the level of the mitral annulus, VTI-Reg $g_{M V}$ velocity time integral of the systolic regurgitant transmitral blood flow at the level of the mitral valve annulus

LVEF of $30 \%$ or by a LVEDV of $200 \mathrm{ml}$ at a LVEF of $60 \%$ (brightened red dot in Fig. 3).

In a CI-HR diagram with respect to different $\mathrm{RF}$ a borderline region to differentiate between normal conditions and cardiac decompensation can be marked at the limit of CI of $2.2 \mathrm{l} / \mathrm{min} / \mathrm{m}^{2}$ (red bar in Fig. 4). In accordance with the previous diagrams (Figs. 2, 3) $\mathrm{LVSV}_{\text {eff }}$ must be $\geq 60 \mathrm{ml}$ and $\mathrm{HR} \geq 65 / \mathrm{min}$ to ensure a CI within normal ranges. The slope of the CI-HR-relationship decreases with increasing RF (dotted lines in Fig. 4). The pathophysiological consequence to ensure a sufficient $\mathrm{CO}$ or $\mathrm{CI}$ is the increase of $\mathrm{HR}$ (red bar in Fig. 4).

If the mean values of CI and HR of the recent TMVR trials [1-3] are put into the diagram, the colored dots represent the respective relationships (Fig. 4). CI-values of 


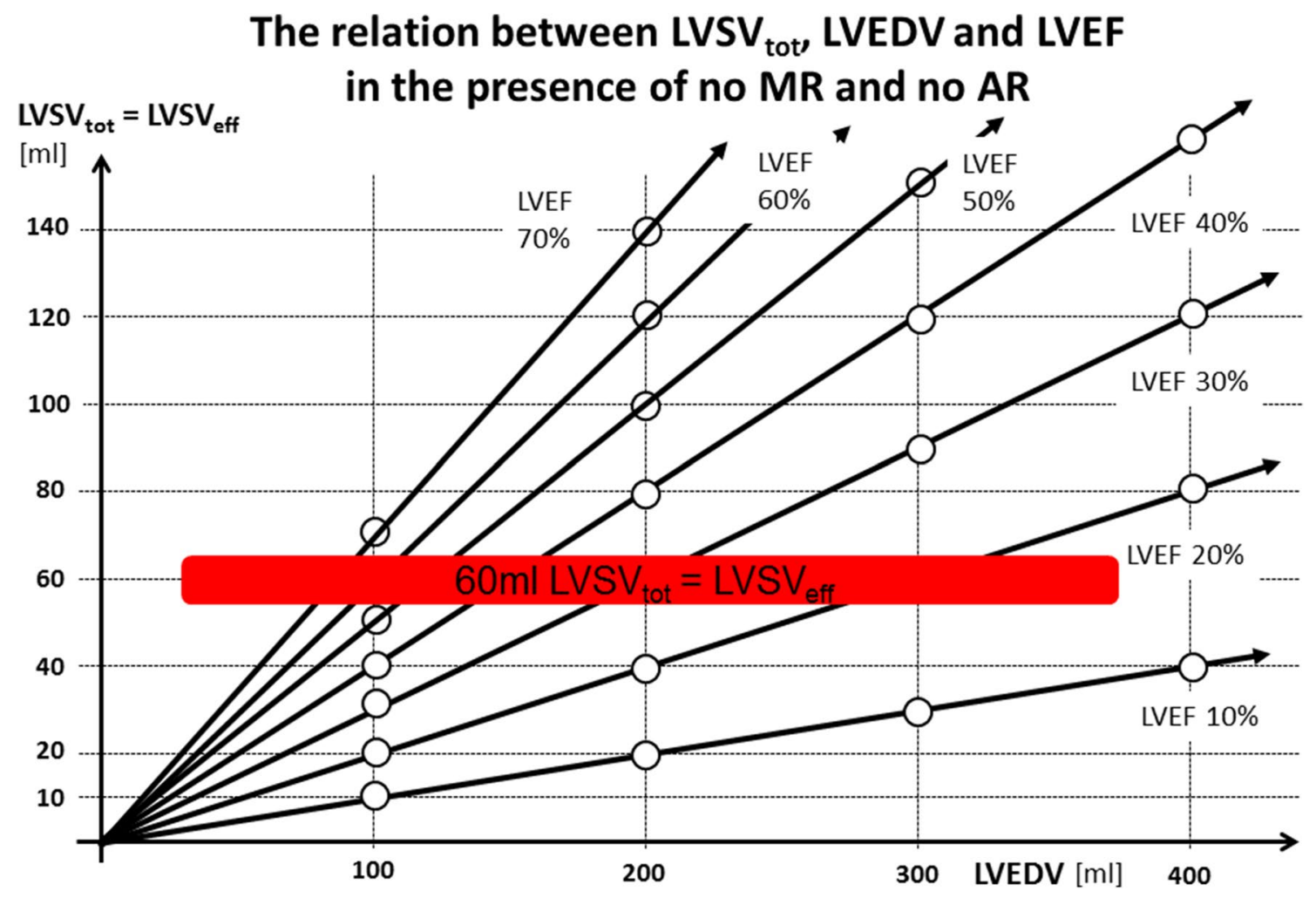

Fig. 2 The relation between total left ventricular (LV) stroke volume $\left(\mathrm{LVSV}_{\text {tot }}\right)$ and LV end-diastolic volume (LVEDV) with respect to LV ejection fraction (LVEF) in the presence of no mitral regurgitation
(MR) and no aortic regurgitation (AR): $L V S V_{\text {eff }} \mathrm{LV}$ effective stroke volume, $C O$ cardiac output, $C I$ cardiac index (additional explanations in the text) the recent TMVR trials were taken or calculated by the $\mathrm{LVSV}_{\text {tot }}, \mathrm{LVSV}_{\text {eff }}$, and $\mathrm{RegVol}_{\mathrm{MV}}$-values presented in the literature [1-3]. In COAPT HR was not listed, thus, a HR of $65-70 / \mathrm{min}$ for cardiovascular patients under OMT was taken for calculation. As obviously shown, all colored dots are below the red bar, which represents the borderline range of $\mathrm{CI}$ between normal conditions and cardiogenic shock. As also illustrated by the arrows HR has to be much higher in all recent TMVR trials than presented in the literature or then the HR ranges of OMT to ensure CI $>2.2 \mathrm{l} /$ $\mathrm{min} / \mathrm{m}^{2}$ (colored arrows in Fig. 4).

The well-known EROA-LVEDV diagram adapted according to Grayburn et al. [12] should illustrate the proportionality between EROA and LVEDV in patients with severe FMR with a border area. Below this area non severe FMR is characterized. Above this area Grayburn et al. proposed to use the term "disproportionate" severe FMR [12]. Grayburn et al. described the diagnostic scenario that "physicians should seek to determine whether the estimated degree of MR is expected or proportionate to the degree of LV dilatation, or alternatively, whether the severity of MR is unexpected or disproportionate to the degree of LV enlargement" [12].
If the mean values of EROA and LVEDV of the recent TMVR trials [1-3] are put into the diagram, the brightened colored dots represent the respective relationships (Fig. 5). However, if these values are corrected with respect to plausible hemodynamics - that means $\mathrm{RegVol}_{\mathrm{MV}}$ or EROA were reduced to ensure at least borderline CI of $2.21 / \mathrm{min} / \mathrm{m}^{2}$-all these brightened dots shift into the area of non-severe FMR (colored dots in Fig. 5).

In all figures two dots are presented for the COAPT trial. The two dots are explained by the values reported in the literature about COAPT $[2,4]$. The first reported $\mathrm{LVSV}_{\text {tot }}$ by planimetry in COAPT was $51 \mathrm{ml}$ and the $\mathrm{RegVol}_{\mathrm{MV}}$ was $59 \mathrm{ml}$ which suggests overestimation of EROA and $\mathrm{RegVol}_{\mathrm{MV}}$, underestimation of LVEDV, or both due to the impossibility of the specified values [2]. If $51 \mathrm{ml}$ as $L_{V S V}$ eff in the presence of $60 \mathrm{ml}$ of $\mathrm{LVSV}_{\text {tot }}$ are assumed, a fully different scenario with a mild FMR of $8 \mathrm{ml}$ with a corresponding RF of $14 \%$ is described (device cohort). 


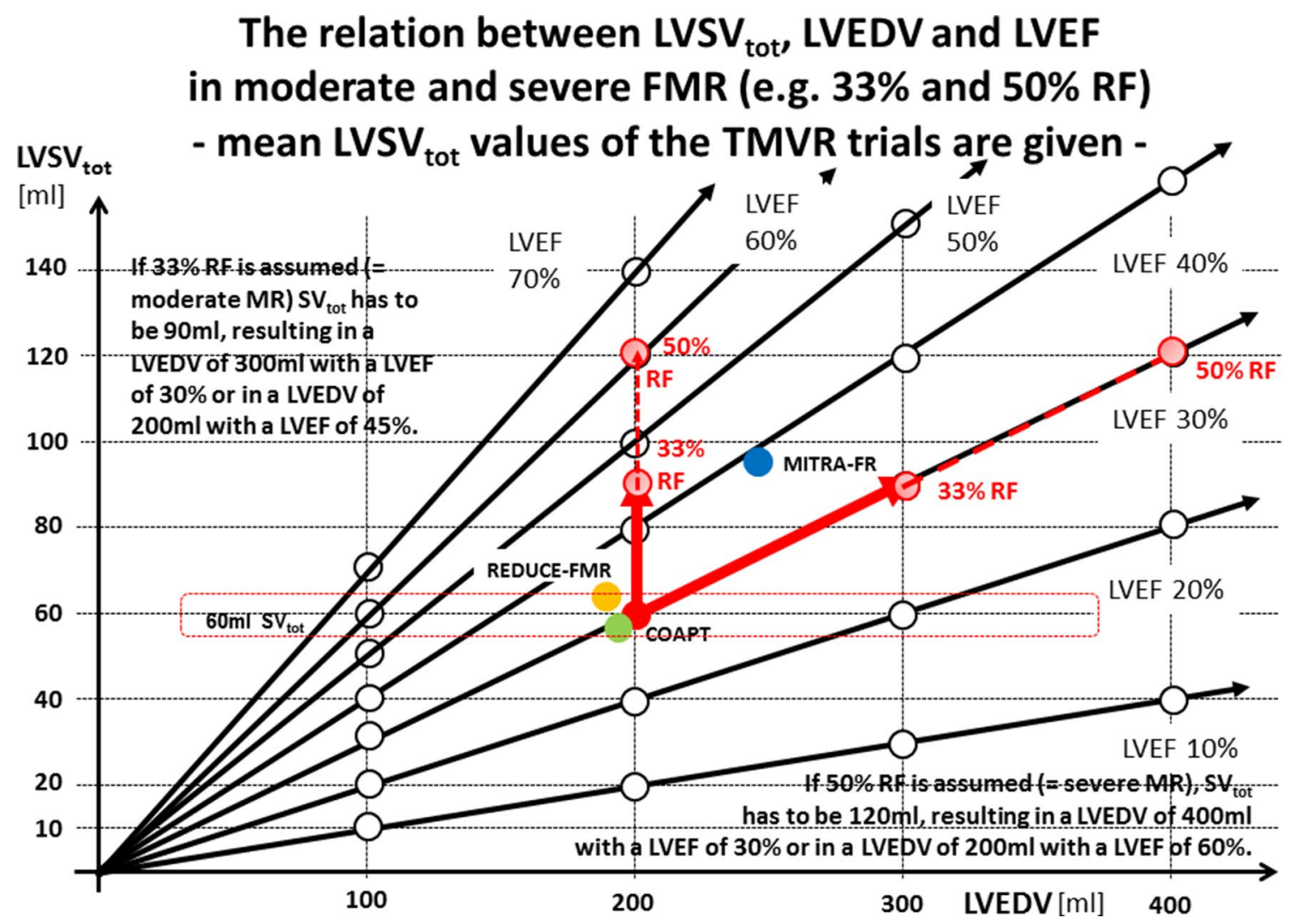

Fig. 3 The relation between total left ventricular (LV) stroke volume $\left(\mathrm{LVSV}_{\text {tot }}\right), \mathrm{LV}$ end-diastolic volume (LVEDV) and LV ejection fraction (LVEF) in moderate and severe mitral regurgitation (MR) (e.g. $33 \%$ and $50 \% \mathrm{RF}) . L V S V_{\text {eff }} \mathrm{LV}$ effective stroke volume, $C O$ cardiac output, $C I$ cardiac index. Mean values of LVSV $_{\text {tot }}$ and LVEDV presented in recent transcatheter mitral valve repair (TMVR) trials are shown in colored dots (green dots COAPT, blue dots MITRA-FR, and orange dots REDUCE-FMR). The red dot displays a left ventricle with a LVEDV of $200 \mathrm{ml}$ and a $\mathrm{LVSV}_{\text {eff }}$ of $60 \mathrm{ml}$; the calculated

\section{Conclusions}

With respect to hemodynamic implausibility of the echocardiographic data presented in the recent TMVR trials [1-3] it might be allowed to search for the reasons for this scenario. If RegVol $\mathrm{MV}$, LVEDV, LVEF and $\mathrm{LVSV}_{\text {tot }}$ are not conclusive and plausible, the following conclusions can be drawn: $\operatorname{RegVol}_{\mathrm{MV}}$ is obviously overestimated and planimetry-derived LVEDV is obviously underestimated. Thus, either the methods used should not be applied anymore or they should be applied correctly.

The assessment of MR severity by the echocardiographic "integrated approach" described by the current guideline recommendations is primarily based on semiquantitative analysis of semiquantitative parameters describing MR severity [8, 9, 23]. However, these parameters including the 2D-PISA approach have inherent problems to be methodically prone to errors. The colour flow jet area in the left
LVSV $_{\text {tot }}$ and LVEDV values in the presence of a LVEF of $30 \%$ in a moderate FMR (regurgitant fraction, $\mathrm{RF}=33 \%$ ) are $\mathrm{LVSV}_{\text {tot }}=90 \mathrm{ml}$ and $\mathrm{LVEDV}=300 \mathrm{ml}$ (hollow red dots), in a severe FMR $(\mathrm{RF}=50 \%)$ are $\mathrm{LVSV}_{\text {tot }}=120 \mathrm{ml}$ and $\mathrm{LVEDV}=400 \mathrm{ml}$ (hollow red dots); the calculated LVSV tot and LVEF values in the presence of LVEDV of $200 \mathrm{ml}$ in a moderate FMR (RF=33\%) $\mathrm{LVSV}_{\text {tot }}$ has to be $90 \mathrm{ml}$ and LVEF $45 \%$ (hollow red dots), in a severe FMR $(\mathrm{RF}=50 \%) \mathrm{LVSV}_{\text {tot }}$ has to be $120 \mathrm{ml}$ and LVEF $60 \%$ (hollow red dots) (additional explanations in the text)

atrium and its relation to the left atrial size depends on several methodological, anatomic, and pathophysiological factors [26]. Because of many factors, no standardization to adjust the colour flow jet area in MR patients is possible. In consequence, the approach of MR grading based on colour flow jet area is not recommended anymore [8]. The vena contracta (VC) by colour coded Doppler was described in MR patients in the parasternal long axis view because of better axial resolution in comparison to inferior lateral resolution in apical views [27]. Prerequisite of the VC method is the acquisition of the correct longitudinal sectional plane through the regurgitant jet to minimize underestimation beside methodological factors of ultrasound machine settings. Considering the mathematical model of the 2D-PISA method the frequent misuse can be explained e.g. by a inappropriate application in eccentrical jet formations or by an overestimation of $\mathrm{RegVol}_{\mathrm{MV}}$ by measuring improper PISA radius at false time points and/or at the $\mathrm{VC}$ instead of the 


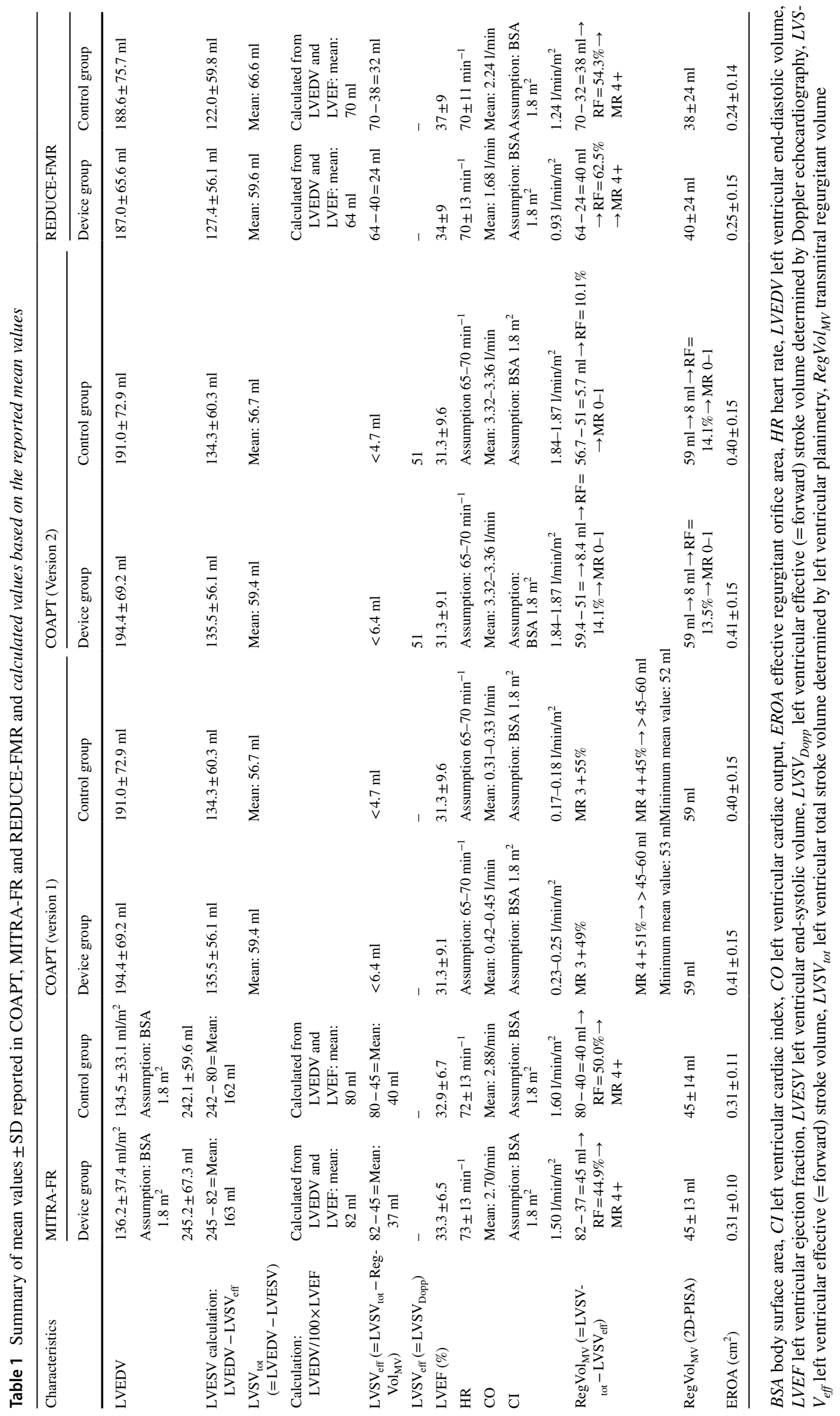




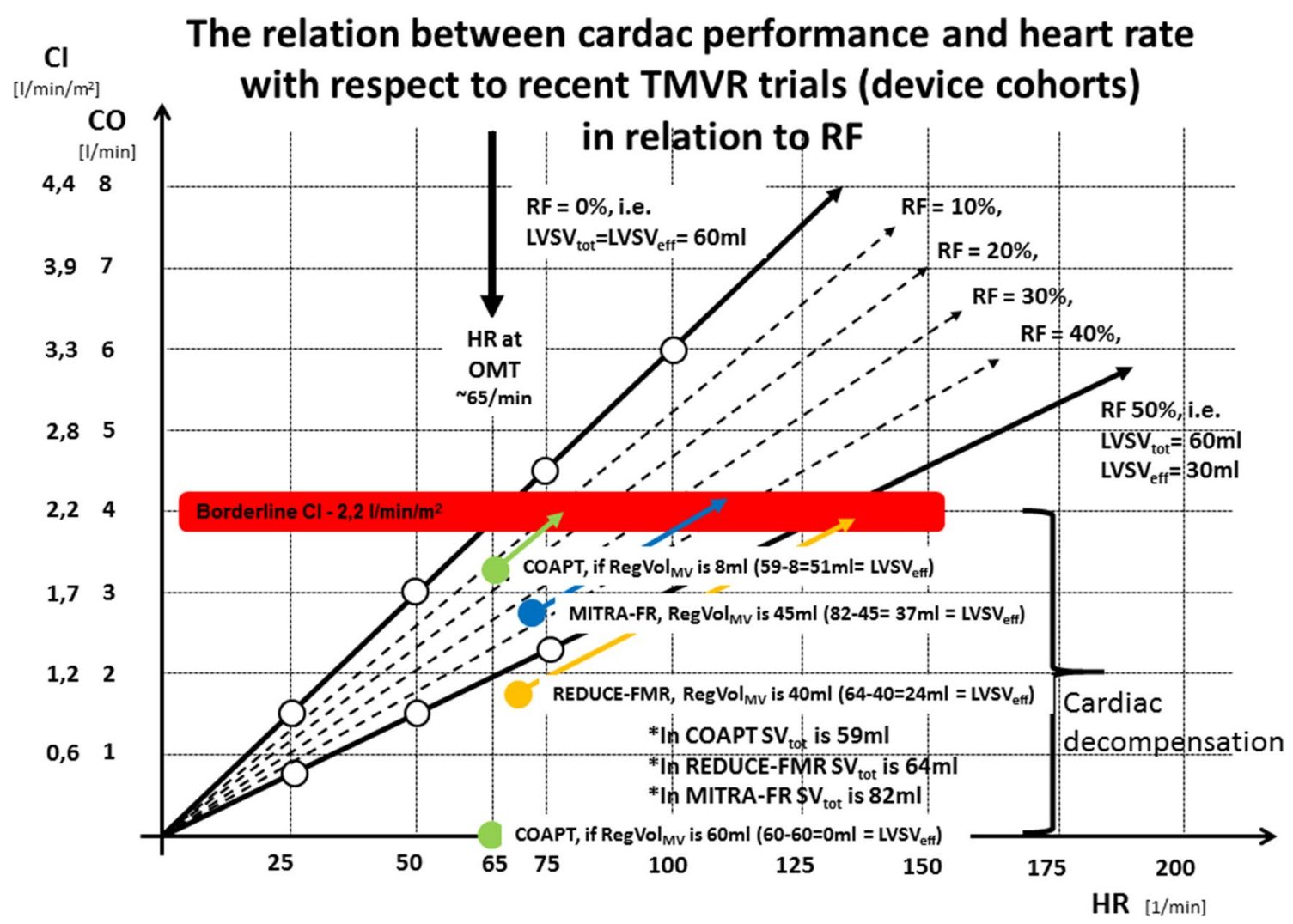

Fig. 4 The relation between cardiac performance ( $\mathrm{CO}$ cardiac output, $C I$ cardiac index) and heart rate (HR) with respect to regurgitant fraction (RF): $L V S V_{\text {tot }}$ total left ventricular (LV) stroke volume, $L V S$ $V_{\text {eff }}$ effective LV stroke volume, $\operatorname{RegVol}_{M V}$ regurgitant volume, OMT optimal medical treatment. Mean values of CI and HR presented in recent transcatheter mitral valve repair (TMVR) trials are illustrated by colored dots (green dots COAPT-version 1: $\mathrm{LVSV}_{\text {tot }}=59 \mathrm{ml}$, $\mathrm{RegVol}_{\mathrm{MV}} 59 \mathrm{ml}$, HR presumably about 70/min during OMT; version

entry of the EROA [28]. The shape of the EROA and the jet direction are colour coded parameters yielding information to assume a relevant MR [9]. However, both entities should serve as a starting point for a quantitative MR assessment. The systolic flow reversal in the pulmonary veins is influenced by the jet direction towards the respective pulmonary veins, the size of the left atrium, and LV contractility causing over- as well as underestimation of MR severity [29]. The intensity of the MR-signal of the transmitral regurgitation using continuous wave Doppler is not recommended for assessing MR severity due to several practical and methodological limitations [8]. The ratio between transmitral velocity time integral (VTI) and flow velocity within the LVOT $\left(\mathrm{VTI}_{\mathrm{MV}} / \mathrm{VTI}_{\mathrm{LVOT}}\right)$ seems to be suitable for a grading approach of MR severity, if the sample volumes are properly positioned, ultrasound beam alignment is parallel to the blood flow, MV stenosis or aortic valve regurgitation
$2-\mathrm{LVSV}_{\text {tot }}=59 \mathrm{ml}, \mathrm{LVSV}_{\text {eff }}=51 \mathrm{ml}, \operatorname{RegVol}_{\mathrm{MV}} 8 \mathrm{ml}$, HR presumably about 70/min during OMT), blue dots MITRA-FR (LVSV ${ }_{\text {tot }}=82 \mathrm{ml}$, RegVol $_{\mathrm{MV}} 45 \mathrm{ml}$, HR 73/min), and orange dots REDUCE-FMR $\left(\right.$ LVSV $_{\text {tot }}=64 \mathrm{ml}, \mathrm{RegVol}_{\mathrm{MV}} 40 \mathrm{ml}, \mathrm{HR} 70 / \mathrm{min}$ ). Thus, calculated HR in the presence of the reported RF to ensure a CI $>2.21 / \mathrm{min} / \mathrm{m}^{2}$ is illustrated by colored arrows (COAPT-version 1: not possible; version 2 about 77/min), MITRA-FR about 110/min, REDUCE-FMR about $130 / \mathrm{min}$ ) (additional explanations in the text)

as well as mitral annular dilatation and atrial fibrillation is absent [30]. Due to all these multiple limitations of the semiquantitative parameters it might be necessary to assess quantitatively $\mathrm{LVSV}_{\text {tot }}, \mathrm{LVSV}_{\text {eff }}$ and $\mathrm{RegVol}_{\mathrm{MV}}$ in a similar approach as currently used in cardiac magnetic resonance, CMR [31-33]. If echocardiographic measurements provide inconsistent results for $\mathrm{LVSV}_{\text {tot }}, \mathrm{LVSV}_{\mathrm{eff}}$ and $\mathrm{RegVol}_{\mathrm{MV}}$, the most likely explanation are obviously measurement errors due to methodological factors.

In HF patients with FMR recently two "hemodynamic pathways" have been described to characterize pathophysiological differences [19]. Firstly, LV remodeling defined by LV hypertrophy, LV dilatation, and LV sphericity causes papillary muscle displacement and widening of the mitral annulus with a consecutive FMR. This FMR type should be characterized by a linear relationship between LVEDV and EROA and has been named "proportionate MR". Secondly, a 


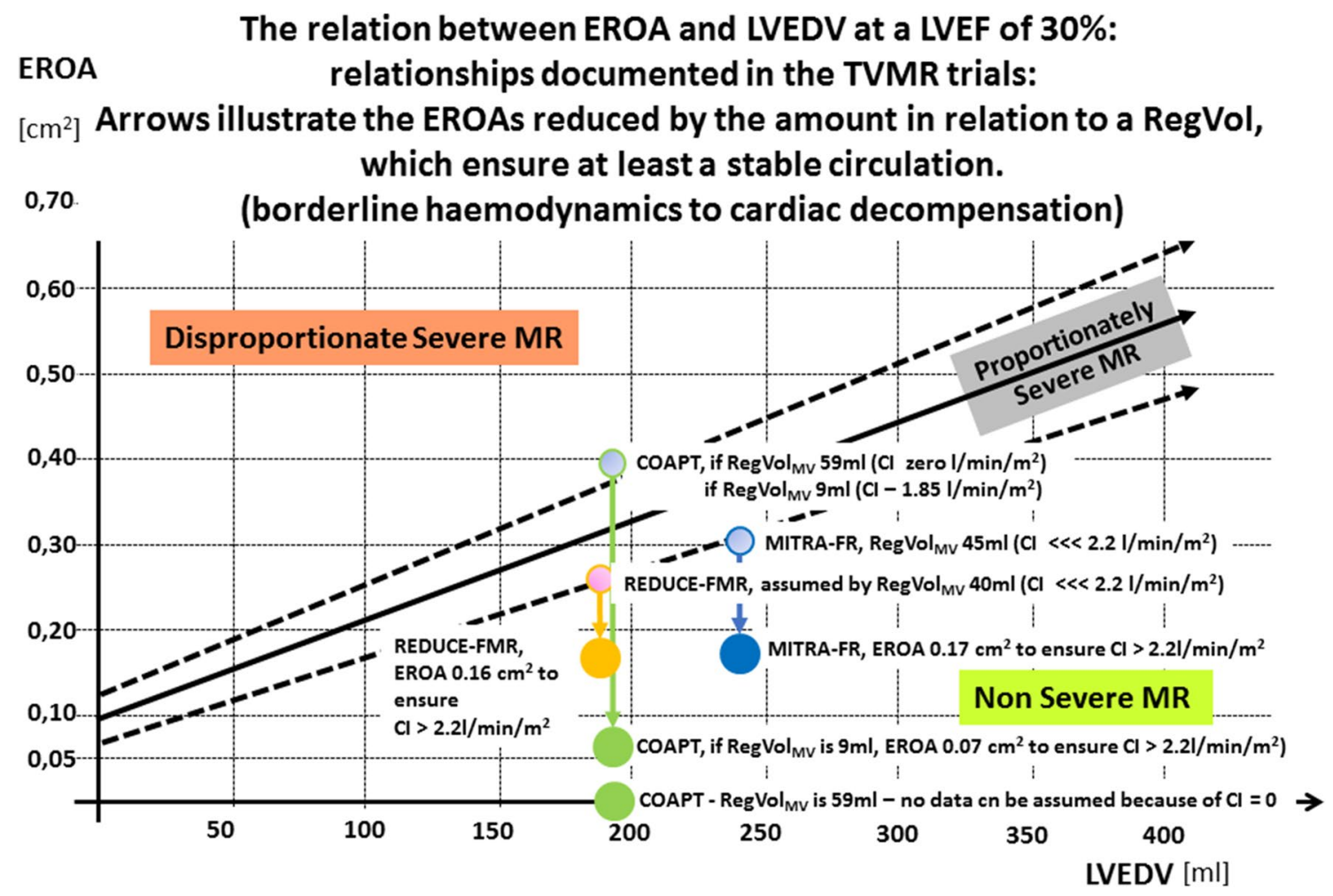

Fig. 5 The relation between effective regurgitant orifice area (EROA) and left ventricular (LV) end-diastolic volume (LVEDV) at a LV ejection fraction (LVEF) about 30\% [6]: the arrows illustrate the respective calculated EROAs presented in recent transcatheter mitral valve repair (TMVR) trials reduced by the amount in relation to a regurgitant volume $\left(\mathrm{RegVol}_{\mathrm{MV}}\right)$, which ensure at least a cardiac index (CI) $>2.21 / \mathrm{min} / \mathrm{m}^{2}$. Mean values of EROA and LVEDV are given for

"disproportionate FMR type" should be possible mainly due to LV dyssynchrony based on electrical conduction delay. This FMR type should be characterized by a greater MR severity than expected solely by LVEDV changes independent of LV geometry [19]. The percentage of HF patient with bundle branch block and FMR in the recent TMVR trials, who primarily are candidates for resynchronization therapy according to recent guidelines [34], has not been transparently presented. However, it was suggested that localized LV remodeling - especially regional wall motion abnormalities of the inferoposterior or lateral wall" - can induce dyssynchronous contraction resulting in a relevant "disproportionate FMR',

However, the introduction of the terms "proportionate" and "disproportionate" FMR is misleading, because $\mathrm{RegVol}_{\mathrm{MV}}$ has to be proportional to EROA in a system of communicating vessels (Fig. 1) at a single beat-to-beat measurement. Considering the single timepoint measurement of the PISA radius within the cardiac cycle there are sources of errors in quantifying $\operatorname{Reg} \mathrm{Vol}_{\mathrm{MV}}$ due to the dynamic nature green hollow dots COAPT [2, 10, 12], blue hollow dots MITRA-FR [1], and pink hollow dots REDUCE-FMR (assumed mean EROA of $0.26 \mathrm{~cm}^{2}$ ) [3]. If the EROA is reduced according to laws of rheology and physics, the EROAs of the filled circles have to be assumed in the recent TMVR trials (green dots COAPT, blue dots MITRA-FR, and orange dots REDUCE-FMR) (additional explanations in the text)

of MR within systole. However, if $\mathrm{RegVol}_{\mathrm{MV}}$ is under- or overestimated by this 2D-PISA approach, it is simply a measurement error, which reflects an incorrect assessment of $\mathrm{Reg} \mathrm{Vol}_{\mathrm{MV}}$. Inherently, physical laws of conservation of mass and energy cannot be neglected using echocardiography meaning that blood flow velocities at defined orifices are proportional in a system of communicating tubes (Fig. 1). Thus, the basic question raises whether a "disproportionate" FMR can be possible anyway. Instead of arithmetic juggling with inconsistent data the aim of a comprehensive echocardiography should be the correct assessment of conclusive values of $\mathrm{LVSV}_{\mathrm{eff}}, \mathrm{LVSV}_{\text {tot }}$, LVEF and $\mathrm{RegVol}_{\mathrm{MV}}$ in patients with FMR.

A complete other discussion are dynamic changes of the MR severity with changes of pre- and afterload [35]. It is obviously that RF is altered with increasing $\mathrm{CO}$ at the same heart rate, if preload or afterload is decreased, e.g. during sedation. It can be assumed, that RF will disproportionately increase with increasing afterload in FMR patients with advanced HF stages. To proof this concept of 
an "overproportionate FMR" at minimum two timepoint measurements at different afterload conditions are necessary. It can also be speculated that increased LV wall stress causes more LV remodeling with PM displacement, MV annulus dilatation and leaflet tenting supporting a higher risk of the development of relevant FMR described by the concept of "MR begets MR" in congestive HF [36]. However, again to proof this concept at minimum two timepoint measurements during follow-up under comparable circulatory conditions are necessary. The dynamic changes of MR severity with changes of pre- and afterload underline the importance to standardize measurement conditions during echocardiography-especially in TMVR trials. It is highly questionable to accept a baseline TTE within 90 days and a baseline TEE within 180 days prior to intervention as described in the COAPT Supplementary Appendix [2]. Baseline characteristics defined in this way might be scrutinized with respect to the possible changes of FMR severity due to several reasons.
A comparison between a pre-interventional state the day before intervention and a post-interventional state at hospital discharge during comparable conditions-especially at the same heart rate, the same systemic blood pressure and the same drug treatment-should be the prerequisite for a verifiable documentation in clinical trials.

This unfortunate situation of implausible echocardiographic assessment in FMR patients mandates the integration of "hemodynamic conclusiveness" into the recent "integrated approach" $[8,9,18]$. New diagnostic algorithms apart from guidelines $[8,9]$ to „identify echocardiographic characteristics that predict favourable outcomes after TMVR in heart failure patients with severe secondary MR “ [10] are highly debatable - especially if inconsistent data are followed by treatment recommendations. A greater transparency of all trial data would presumably be helpful for a better understanding. The incongruencies of the reported hemodynamic values in patients with FMR in the recent

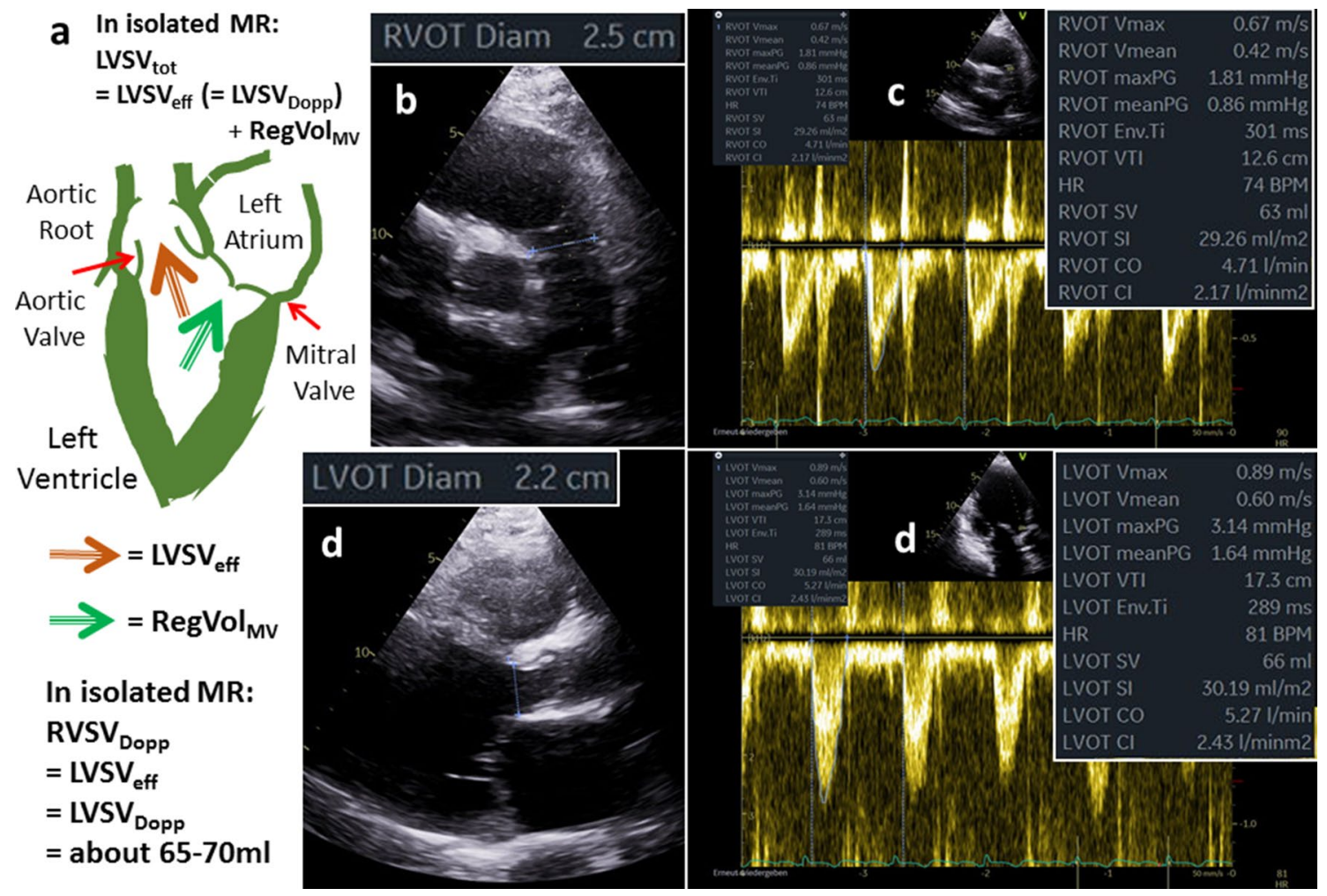

Fig. 6 Illustration of quantitative assessment of left ventricular (LV) volumes in a patient with isolated functional mitral regurgitation (FMR) — part 1: a scheme of LV effective stroke volume (LVSV $\left.{ }_{\text {eff }}\right)$ and regurgitant volume $(\operatorname{RegVol} \mathrm{MV})$ in isolated FMR (a); measurements of right ventricular (RV) and LV stroke volume by Doppler echocardiography $\left(\mathrm{RVSV}_{\text {Dopp }}\right.$, $\mathrm{LVSV}_{\text {Dopp }}$ ) by determination of the diameter of the RV outflow tract (RVOT) (b) and the velocity time integral (VTI) of the RVOT (RVOT VTI) (c) and by determination of the diameter of the LV outflow tract (LVOT) (d) and the LVOT VTI (). In isolated FMR RVSV $V_{\text {Dopp }}$ is equal to $\operatorname{RVLV}_{\text {Dopp, }}$, which represents $\mathrm{LVSV}_{\text {eff }}$ as well as RVSV eff $^{\text {. }} \mathrm{LVSV}_{\text {eff }}$ is between 65 and $70 \mathrm{ml}$ in this case 
TMVR trials illustrates the recent echocardiographic weakness in routine practice. The term "disproportionate" FMR is hardly to accept because a disproportionateness of hemodynamics might be just a proof of measuring error or simply a myth.

The objective, reproducible and transparent assessment of echocardiographic parameters for LV function and RF estimation in FMR patients will be the key for a proper decision making.

\section{Proposal of an extended transparent echocardiographic documentation focusing on hemodynamic plausibility in FMR patients FMR}

A comprehensive echocardiography should integrate the estimating of cardiovascular parameters by a plausibility-check of the data. Despite the fact, that all cardiologists know, that the accurate assessment of LV volumes and LV function by echocardiography is well possible and methodological limitations in measuring LV volumes and LVEV have to be considered, the echocardiographic documentation with respect to its transparency, reproducibility and objectivity is illustrated regarding to the intention of an imaging journal (Figs. 6, 7, 8, 9).

The quantitative approach of FMR assessment by echocardiography is challenging. The quantitative assessment of LV volumes is highly criticized because of the necessity to determine several parameters, which are all prone to measuring errors that are squared in the respective calculations [8, 9]. Nevertheless, in isolated FMR, the LVSV is determined by LV planimetry using the monoplane, biplane, triplane or 3D approach. The $\mathrm{LVSV}_{\text {eff }}$ is measured by Doppler calculations of forward stroke volume using cross sectional area of the LVOT and the PW-Doppler velocity time integral (VTI) of the LVOT. In patients

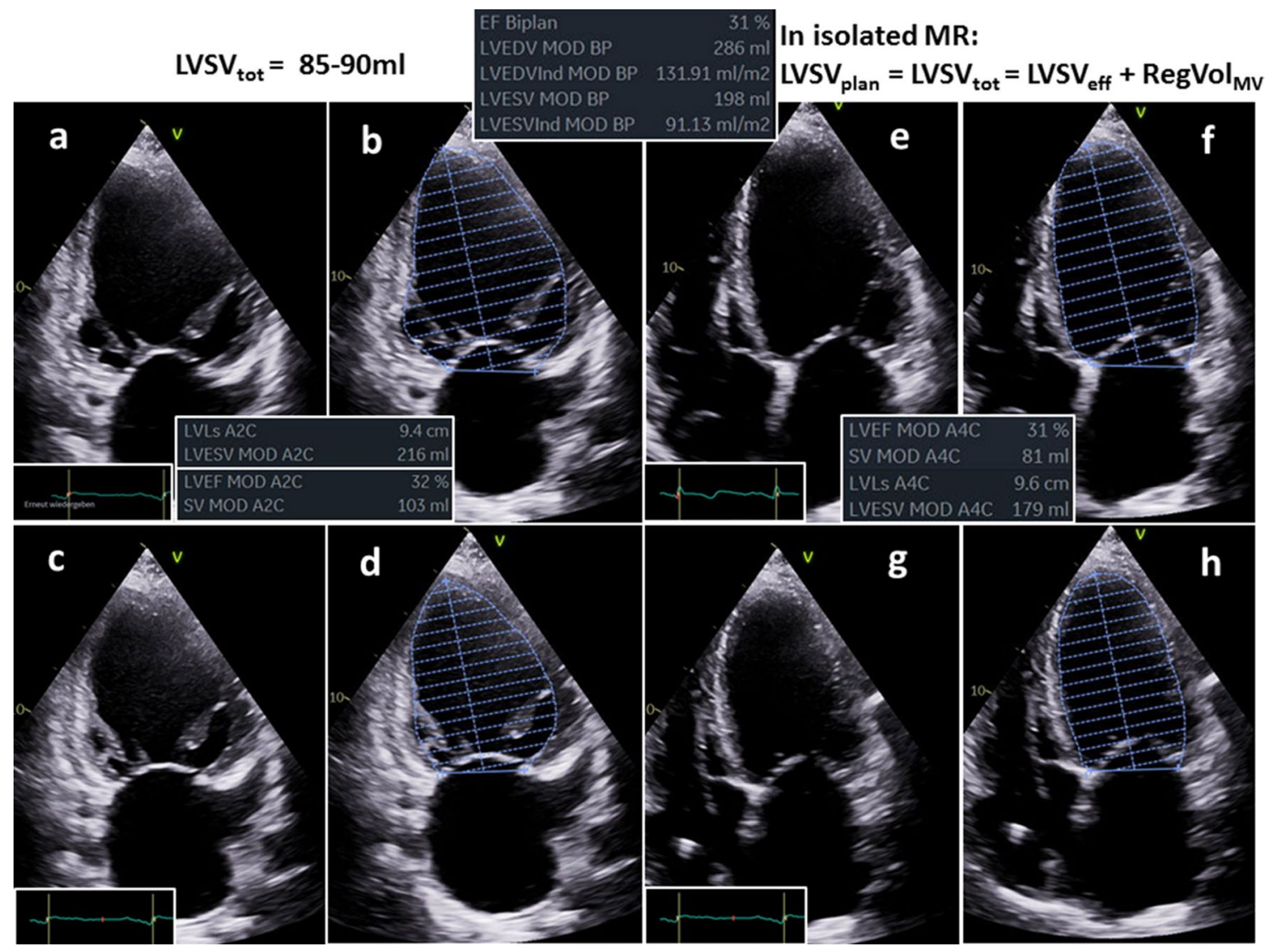

Fig. 7 Illustration of quantitative assessment of left ventricular (LV) volumes in the same patient with isolated functional mitral regurgitation (FMR) as shown in Fig. 1-part 2: determination of left ventricular $(\mathrm{LV})$ total stroke volume $\left(\mathrm{LVSV}_{\text {tot }}\right)$ by biplane planimetry using Simpson's method; planimetry of the 2-chamber view during diastole (a, b) and systole (c, d), planimetry of the 4-chamber view during diastole $(\mathbf{e}, \mathbf{f})$ and systole $(\mathbf{g}, \mathbf{h})$; the biplane LV planimetry enables the determination of $\mathrm{LVSV}_{\text {tot }}$, which is the sum of LV effective stroke volume $\left(\mathrm{LVSV}_{\mathrm{eff}}\right)$ and of the regurgitant volume $\left(\mathrm{RegVol}_{\mathrm{MV}}\right) ; \mathrm{LVSV}_{\text {tot }}$ is between 85 and $90 \mathrm{ml}$ in this case 


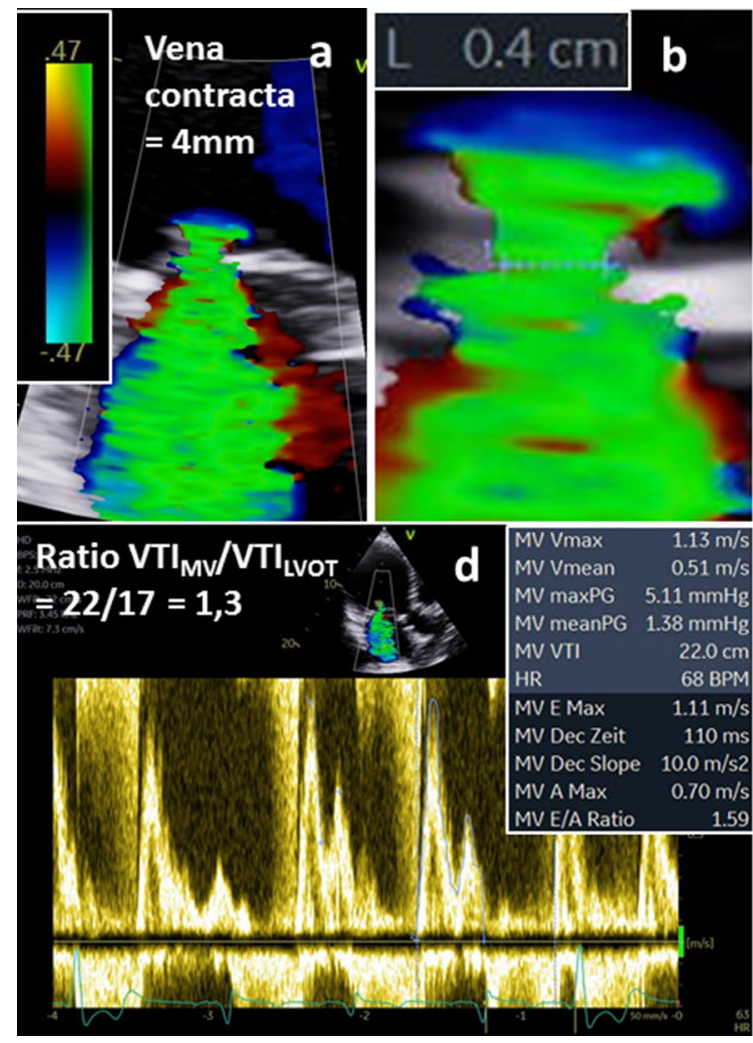

Fig. 8 Illustration of quantitative assessment of left ventricular (LV) volumes in the same patient with isolated functional mitral regurgitation (FMR) as shown in Figs. 1 and 2-part 3: documentation of the FMR with a central jet formation, the jet area, the proximal convergence areas, and the vena contracta (VC) with a Nyquist limit of $47 \mathrm{~cm} / \mathrm{s}$ (a), VC measurement with $4 \mathrm{~mm}$ (b), the basal septal myocardial velocity for calculation of $\mathrm{E}^{\mathrm{E}} \mathrm{E}^{\prime}(\mathbf{c})$, the pulsed wave Doppler

with combined aortic valve disease the $\mathrm{LVSV}_{\text {eff }}$ can be determined by Doppler calculations of SV using cross sectional area the right ventricular outflow tract (RVOT) and the respective PW-Doppler VTI of the RVOT which is not common use in clinical routine echocardiography. As illustrated LV volumes and $\mathrm{Reg} \mathrm{Vol}_{\mathrm{MV}}$ can be correctly calculated by the differences of $\mathrm{LVSV}_{\text {tot }}$ and $\mathrm{LVSV}_{\text {eff }}$ or $\mathrm{RVSV}_{\text {eff }}$, and in few cases, in which the 2D-PISA method can adequately be used, the calculated $\mathrm{RegVol}_{\mathrm{MV}}$ corresponds to the $\mathrm{RegVol}_{\mathrm{MV}}$ determined by the 2D-PISA method (Figs. 6, 7, 8, 9). If all parameters can be assessed, a cross-check can be well performed with respect to plausible hemodynamics [37]. To provide a precise echocardiographic characterization of FMR severity the presented quantitative TTE approach might be additionally added to the "up to now integrated approach" to provide a more

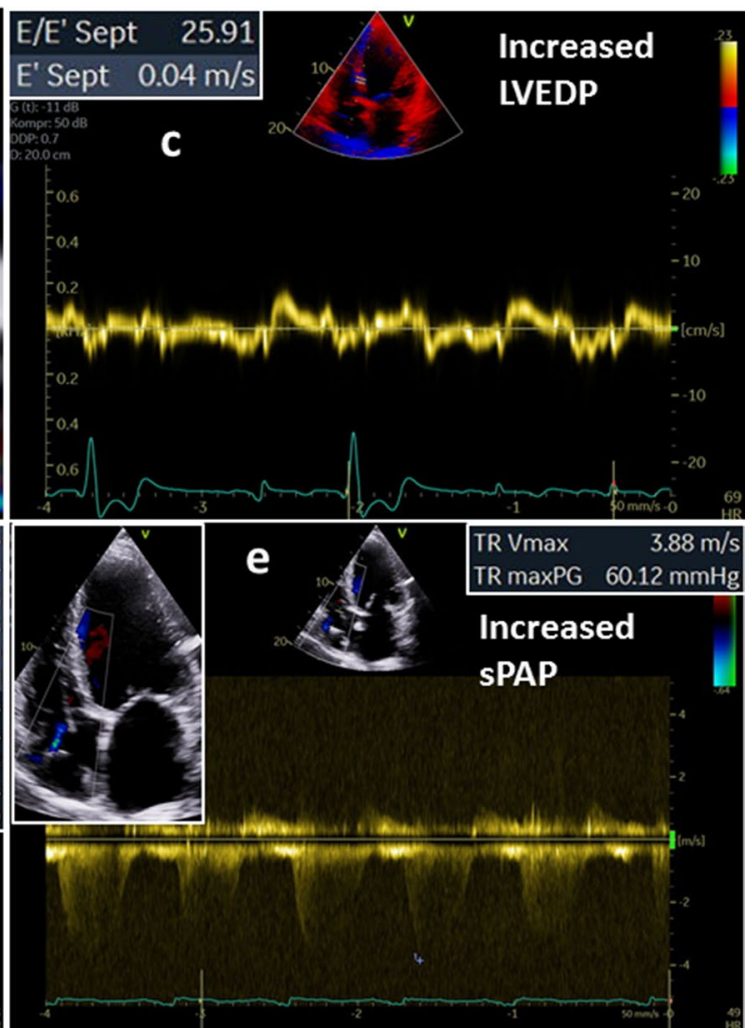

spectrum for determination of E velocity, the E/A-ratio and the ratio between transmitral velocity time integral (VTI) and flow velocity within the LVOT $\left(\mathrm{VTI}_{\mathrm{MV}} / \mathrm{VTI}_{\mathrm{LVOT}}\right)(\mathbf{d})$, and the continuous wave Doppler spectrum of the transtricuspid regurgitation for estimation of the systolic pulmonary arterial pressure (sPAP) (e); increased E/E', increased E-velocity, increased $\mathrm{VTI}_{\mathrm{MV}} / \mathrm{VTI}_{\mathrm{LVOT}}$ and increased sPAP document the secondary cardiac alterations of a relevant MR

reliable and more consistent characterization of the FMR severity.

\section{Summary}

(1) The inconsistencies of the echocardiographic characterization of FMR severity make interpretations about FMR characteristics or generation of algorithms based on the trial results difficult.

(2) The term "disproportionate FMR" is not in line with the physical laws of conservation of mass and energy and can only be explained by inconsistent echocardiographic data. Thus, the term is confusing and should therefore be avoided because a "disproportionate FMR" 

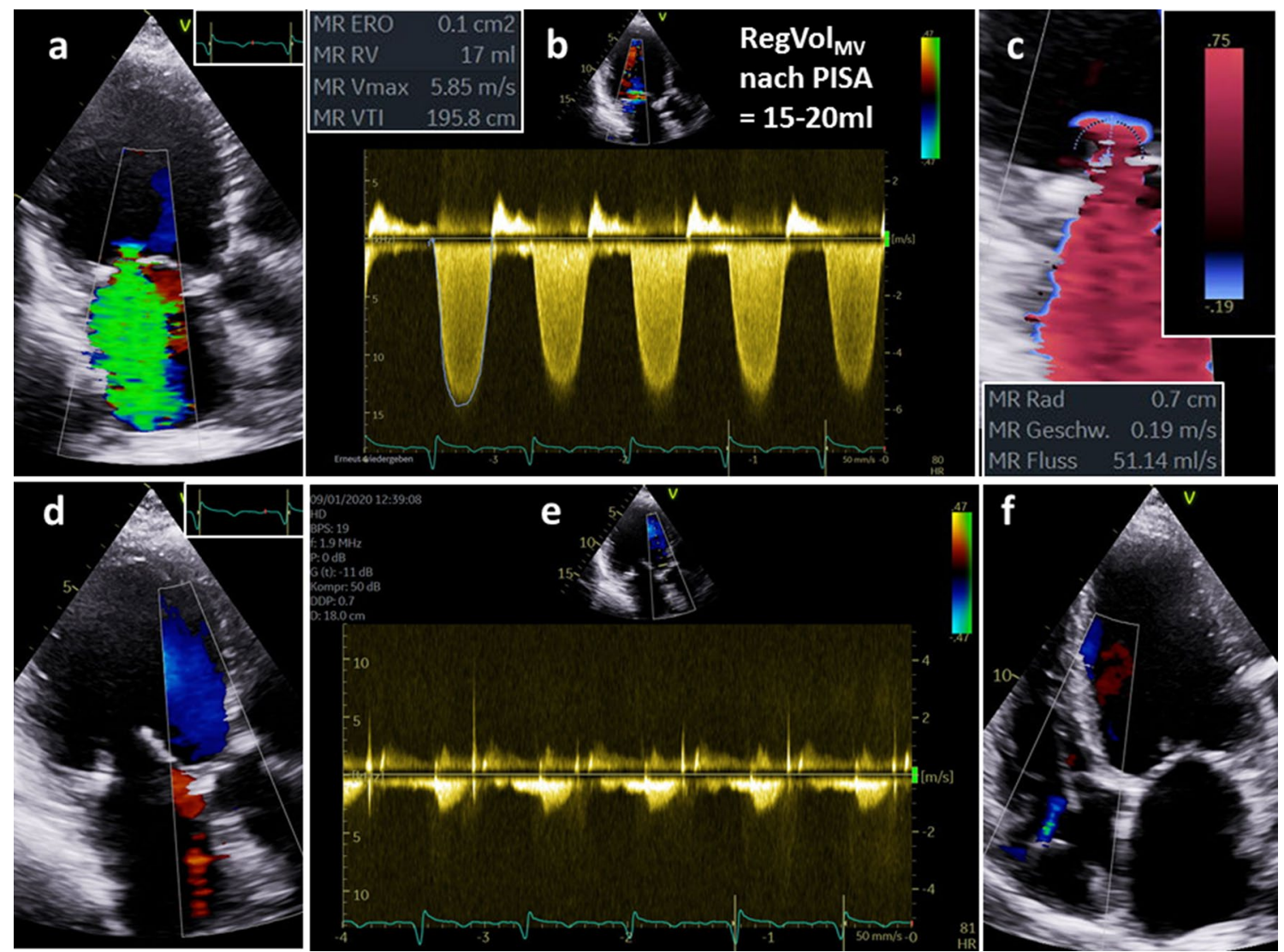

Fig. 9 Illustration of quantitative assessment of left ventricular (LV) volumes in the same patient with isolated functional mitral regurgitation (FMR) as shown in Figs. 1, 2 and 3-part 3: determination of regurgitant volume $\left(\mathrm{RegVol}_{\mathrm{MV}}\right)$ by the 2D-PISA method-the jet phenomenon at systole using a Nyquist limit $47 \mathrm{~cm} / \mathrm{s}$ (a), measurement of the mean and maximum regurgitant velocities (b), labeling of the 2D-PISA radius at a Nyquist limit of $19 \mathrm{~cm} / \mathrm{s}(\mathbf{c})$, the estimation of $\mathrm{RegVol}_{\mathrm{MV}}$ in this case, in which the 2D-PISA method is allowed to

with inconsistent hemodynamics is not possible anyway.

(3) A quantitative approach of FMR grading that includes the accurate quantitative assessment of $\operatorname{LVSV}_{\text {tot }}$, $\mathrm{LVSV}_{\text {eff }}, \mathrm{RegVol}_{\mathrm{MV}}$ and individual RF by echocardiography should be discussed in future recommendations.

Funding Open access funding provided by Projekt DEAL.

\section{Compliance with ethical standards}

\section{Conflict of interest None.}

Open Access This article is licensed under a Creative Commons Attribution 4.0 International License, which permits use, sharing, adaptation, distribution and reproduction in any medium or format, be used, results in a value of about $15-20 \mathrm{ml}$; the volumes $\mathrm{LVSV}_{\text {tot }}$, $\mathrm{LVSV}_{\text {eff }}, \mathrm{RVSV}_{\text {eff }}$, and RegVol $\mathrm{MV}$ have to be conclusive and plausible; exclusion of additional relevant valvular diseases $(\mathbf{d}-\mathbf{f})$; color-coded image of the left ventricular outflow tract during diastolic documents the exclusion of aortic regurgitation (AR) (d), the respective continuous wave Doppler spectrum documents no regurgitant signal (e), and a trace tricuspid regurgitation during systole is documented (f)

as long as you give appropriate credit to the original author(s) and the source, provide a link to the Creative Commons licence, and indicate if changes were made. The images or other third party material in this article are included in the article's Creative Commons licence, unless indicated otherwise in a credit line to the material. If material is not included in the article's Creative Commons licence and your intended use is not permitted by statutory regulation or exceeds the permitted use, you will need to obtain permission directly from the copyright holder. To view a copy of this licence, visit http://creativecommons org/licenses/by/4.0/.

\section{References}

1. Obadia JF, Messika-Zeitoun D, Leurent G, Iung B, Bonnet G, Piriou N, Lefèvre T, Piot C, Rouleau F, Carrié D, Nejjari M, Ohlmann P, Leclercq F, Saint Etienne C, Teiger E, Leroux L, Karam N, Michel N, Gilard M, Donal E, Trochu JN, Cormier B, Armoiry X, Boutitie F, Maucort-Boulch D, Barnel C, Samson G, Guerin P, Vahanian A, Mewton N, MITRA-FR Investigators 
(2018) Percutaneous repair or medical treatment for secondary mitral regurgitation. N Engl J Med 379:2297-2306

2. Stone GW, Lindenfeld J, Abraham WT, Kar S, Lim DS, Mishell JM, Whisenant B, Grayburn PA, Rinaldi M, Kapadia SR, Rajagopal V, Sarembock IJ, Brieke A, Marx SO, Cohen DJ, Weissman NJ, Mack MJ, COAPT Investigators (2018) Transcatheter mitral-valve repair in patients with heart failure. N Engl J Med 379:2307-2318. https://doi.org/10.1056/nejmoa1806640

3. Klaus K, Witte KK, Lipiecki J, Siminiak T, Meredith JT, Malkin CJ, Goldberg SL, Stark MA, von Bardeleben RS, Cremer PC, Jaber WA, Celermajer DS, Kaye DM, Sievert H (2019) The REDUCE FMR Trial: a randomized sham-controlled study of percutaneous mitral annuloplasty in functional mitral regurgitation. JACC Heart Fail 7:945-955. https://doi.org/10.1016/j. jchf.2019.06.011

4. Crestanello JA, Oh JK, Schaff HV (2019) Transcatheter mitral-valve repair in patients with heart failure. N Engl J Med 380:1978. https://doi.org/10.1056/NEJMc1903982

5. Doenst T, Bargenda S, Kirov H, Moschovas A, Tkebuchava S, Safarov R, Diab M, Faerber G (2019) Cardiac surgery 2018 reviewed. Clin Res Cardiol 108:974-989. https://doi. org/10.1007/s00392-019-01470-6

6. Hahn RT (2019) Disproportionate emphasis on proportionate mitral regurgitation-are there better measures of regurgitant severity? JAMA Cardiol. https://doi.org/10.1001/jamacardio .2019 .6235

7. Hagendorff A, Doenst T, Falk V (2019) Echocardiographic assessment of functional mitral regurgitation: opening Pandora's box? ESC Heart Fail 6:678-685. https://doi.org/10.1002/ ehf 2.12491

8. Lancellotti P, Tribouilloy C, Hagendorff A, Popescu BA, Edvardsen T, Pierard LA, Badano L, Zamorano JL, Scientific Document Committee of the EuropeanAssociation of Cardiovascular Imaging (2013) Recommendations for the echocardiographic assessment of native valvular regurgitation: an executive summary from the European Association of Cardiovascular Imaging. Eur Heart J Cardiovasc Imaging 14:611-644

9. Zoghbi WA, Adams D, Bonow RO, Enriquez-Sarano M, Foster E, Grayburn PA, Hahn RT, Han Y, Hung J, Lang RM, Little SH, Shah DJ, Shernan S, Thavendiranathan P, Thomas JD, Weissman NJ (2017) Recommendations for noninvasive evaluation of native valvular regurgitation: a report from the American Society of Echocardiography developed in collaboration with the Society for Cardiovascular Magnetic Resonance. J Am Soc Echocardiogr 30:303-371

10. Asch AF, Grayburn PA, Siegel RJ, Kar S, Lim DS, Zaroff JG, Mishell JM, Whisenant B, Mack MJ, JoAnn Lindenfeld JA, Abraham WT, Stone GW, Weissman NJ, on behalf of the COAPT Investigators (2019) Echocardiographic outcomes after transcatheter leaflet approximation in patients with secondary mitral regurgitation: the COAPT trial. J Am Coll Cardiol 74:2969-2979. https ://doi.org/10.1016/j.jacc.2019.09.017

11. Gaasch WH, Aurigemma GP, Meyer TE (2020) An appraisal of the association of clinical outcomes with the severity of regurgitant volume relative to end-diastolic volume in patients with secondary mitral regurgitation. JAMA Cardiol. https://doi. org/10.1001/jamacardio.2019.5980

12. Grayburn PA, Sannino A, Packer M (2019) Proportionate and disproportionate functional mitral regurgitation: a new conceptual framework that reconciles the results of the MITRA-FR and COAPT trials. JACC Cardiovasc Imaging 12:353-362

13. Arora G, Patel N, Arora P (2018) Futile MITRA-FR and a positive COAPT trial: where does the evidence leave the clinicians? Int J Cardiol Heart Vasc 22:18-19

14. Bartko PE, Arfsten H, Heitzinger G, Pavo N, Toma A, Strunk G, Hengstenberg C, Hülsmann M, Goliasch G (2019) A unifying concept for the quantitative assessment of secondary mitral regurgitation. J Am Coll Cardiol 73:2506-2517. https://doi. org/10.1016/j.jacc.2019.02.075

15. Praz F, Grasso C, Taramasso M, Baumbach A, Piazza N, Tamburino C, Windecker S, Maisano F, Prendergast B (2019) Mitral regurgitation in heart failure: time for a rethink. Eur Heart $\mathrm{J}$ 40:2189-2193. https://doi.org/10.1093/eurheartj/ehz222

16. Drake DH, Zimmerman KG, Sidebotham DA (2019) Transcatheter mitral-valve repair in patients with heart failure. N Engl J Med 380:1978-1979. https://doi.org/10.1056/NEJMc1903982

17. Garbi M, Lancelotti P (2019) Transcatheter mitral-valve repair in patients with heart failure. N Engl J Med 380:1979. https:// doi.org/10.1056/NEJMc1903982

18. Kalavrouziotis D, Voisine P, Mohammadi S (2019) Transcatheter mitral-valve repair in patients with heart failure. N Engl J Med 380:1979-1980. https://doi.org/10.1056/NEJMc1903982

19. Packer M, Grayburn PA (2019) Contrasting effects of pharmacological, procedural, and surgical interventions on proportionate and disproportionate functional mitral regurgitation in chronic heart failure. Circulation 140:779-789. https://doi.org/10.1161/ CIRCULATIONAHA.119.039612

20. Packer M, Grayburn PA (2020) New evidence supporting a novel conceptual framework for distinguishing proportionate and disproportionate functional mitral regurgitation. JAMA Cardiol. https:// doi.org/10.1001/jamacardio.2019.5971

21. Pibarot P, Delgado V, Bax JJ (2019) MITRA-FR vs. COAPT: lessons from two trials with diametrically opposed results. Eur Heart J Cardiovasc Imaging 20:620-624. https://doi.org/10.1093/ehjci/ jez073

22. Senni M, Adamo M, Metra M, Alfieri O, Vahanian A (2019) Treatment of functional mitral regurgitation in chronic heart failure: can we get a 'proof of concept' from the MITRA-FR and COAPT trials? Eur J Heart Fail 21:852-861. https://doi. org/10.1002/ejhf.1491

23. Grayburn PA, Carabello B, Hung J, Gillam LD, Liang D, Mack MJ, McCarthy PM, Miller DC, Trento A, Siegel RJ (2014) Defining "severe" secondary mitral regurgitation: emphasizing an integrated approach. J Am Coll Cardiol 64:2792-2801. https://doi. org/10.1016/j.jacc.2014.10.016

24. Baumgartner H, Hung J, Bermejo J, Chambers JB, Edvardsen T, Goldstein S, Lancellotti P, LeFevre M, Miller F, Otto CM (2017) Recommendations on the echocardiographic assessment of aortic valve stenosis: a focused update from the European Association of Cardiovascular Imaging and the American Society of Echocardiography. Eur Heart J Cardiovasc Imaging 18:254-275. https://doi.org/10.1093/ehjci/jew335

25. Hagendorff A, Knebel F, Helfen A, Knierim J, Sinning C, Stöbe S, Fehske W, Ewen S (2020) Expert consensus document on the assessment of the severity of aortic valve stenosis by echocardiography to provide diagnostic conclusiveness by standardized verifiable documentation. Clin Res Cardiol 109:271-288. https ://doi.org/10.1007/s00392-019-01539-2

26. Baumgartner H, Schima H, Kuhn P (1991) Value and limitations of proximal jet dimensions for the quantitation of valvular regurgitation: an in vitro study using Doppler flow imaging. J Am Soc Echocardiogr 4:57-66

27. Hall SA, Brickner ME, Willett DL, Irani WN, Afridi I, Grayburn PA (1997) Assessment of mitral regurgitation severity by Doppler color flow mapping of the vena contracta. Circulation 95:636-642

28. Bargiggia GS, Tronconi L, Sahn DJ, Recusani F, Raisaro A, De Servi S, Valdes-Cruz LM, Montemartini C (1991) A new method for quantitation of mitral regurgitation based on color flow Doppler imaging of flow convergence proximal to regurgitant orifice. Circulation 84:1481-1489

29. Enriquez-Sarano M, Dujardin KS, Tribouilloy CM, Seward JB, Yoganathan AP, Bailey KR, A J Tajik AJ. (1999) Determinants 
of pulmonary venous flow reversal in mitral regurgitation and its usefulness in determining the severity of regurgitation. Am J Cardiol 83:535-541

30. Tribouilloy C, Shen WF, Rey JL, Adam MC, Lesbre JP (1994) Mitral to aortic velocity-time integral ratio. A non-geometric pulsed-Doppler regurgitant index in isolated pure mitral regurgitation. Eur Heart J 15:1335-1339

31. Thavendiranathan P, Phelan D, Thomas JD, Flamm SD, Marwick TH (2012) Quantitative assessment of mitral regurgitation: validation of new methods. J Am Coll Cardiol 60:1470-1483. https:// doi.org/10.1016/j.jacc.2012.05.048

32. Uretsky S, Gillam L, Lang R, Chaudhry FA, Argulian E, Supariwala A, Gurram S, Jain K, Subero M, Jang JJ, Cohen R, Wolff SD (2015) Discordance between echocardiography and MRI in the assessment of mitral regurgitation severity: a prospective multicenter trial. J Am Coll Cardiol 65:1078-1088. https://doi. org/10.1016/j.jacc.2014.12.047

33. Uretsky S, Argulian E, Narula J, Wolff SD (2018) Use of cardiac magnetic resonance imaging in assessing mitral regurgitation: current evidence. J Am Coll Cardiol 71:547-563. https://doi. org/10.1016/j.jacc.2017.12.009
34. Baumgartner H, Falk V, Bax JJ, De Bonis M, Hamm C, Holm PJ, Iung B, Lancellotti P, Lansac E, Muñoz DR, Rosenhek R, Sjögren J, Mas PT, Vahanian A, Walther T, Wendler O, Windecker S, Zamorano JL, ESC Scientific Document Group (2017) 2017 ESC/EACTS Guidelines for the management of valvular heart disease. Eur Heart J 38:2739-2791. https://doi.org/10.1093/ eurheartj/ehx391

35. Kizilbash AM, Willett DL, Brickner ME, Heinle SK, Grayburn PA (1998) Effects of afterload reduction on vena contracta width in mitral regurgitation. J Am Coll Cardiol 32:427-431

36. Borger MA, Alam A, Murphy PM, Doenst T, David TE (2006) Chronic ischemic mitral regurgitation: repair, replace or rethink? Ann Thorac Surg 81:1153-1161. https://doi.org/10.1016/j.athor acsur.2005.08.080

37. Stöbe S, Kreyer K, Jurisch D, Pfeiffer D, Lavall D, Farese G, Laufs U, Hagendorff A (2020) Echocardiographic analysis of acute effects of percutaneous mitral annuloplasty on severity of secondary mitral regurgitation. ESC Heart Fail. https://doi.org/10.1002/ehf2.12719

Publisher's Note Springer Nature remains neutral with regard to jurisdictional claims in published maps and institutional affiliations. 